\title{
EXPLORING INTERVENTIONS THAT REDUCE LEARNER AVERSION TO WORKING IN TEAMS
}

\author{
Helen Geytenbeek, Dr Lesley Gill, Rachel Byars \\ and Melissa Clarke-Fuller
}

\section{INTRODUCTION}

A real challenge in today's classrooms is learners' resistance to working in teams. This paper explores some of the factors that inform this phenomenon including societal factors such as greater independence, isolation and self-reliance. Given an increased need to be able to work in teams in organisations, employability skills required to successfully transition between the classroom and the workplace are paramount. This paper presents a problem-solving approach using case study methodology, based on the compulsory Level 6 Improving Organisational Performance (IOP) paper, part of a suite of papers in Otago Polytechnic's Bachelor of Applied Management, which aims to develop learners' research skills and teamwork as well as employability skills. Implicit in IOP's learning outcomes is the expectation that learners develop these team skills. As a result, a new emphasis was placed on effective team formation, cohesion and performance for the purpose of reducing learner aversion to working in teams.

IOP is a paper where learners work within a team setting in collaboration with a host organisation (for example, a local restaurant, supermarket or gym) and their academic supervisor (lecturer) to identify and investigate a problem, challenge or opportunity and then propose feasible, implementable outcomes for the organisation. Groups are designed by the lecturer and generally consist of four to five members. The purpose of the paper is to develop the learners' competencies by applying a range of management concepts, theories, frameworks and key analytical tools used in business research. Skills such as problem solving, effective business communication, conflict management and project management form an additional skill set that complements the requirements of the learning outcomes.

The outcomes of the learners' research investigation informs the host organisation's managerial decision-making. Learners apply appropriate research methods to investigate and identify the root cause of the problem or opportunity at issue within the organisation. This course aids in developing learners' employability skills by fostering their ability to critically assess scholarly management science literature, as well as enhancing knowledge creation in real-time business environments, in addition to gaining other skills such as emotional intelligence. 


\section{EMPLOYABILITY SKILLS}

Employability skills are abilities and skills that reduce the gap between theory-filled learners and those who are able to apply their learning directly to the workplace. Carrying out research in Scotland and elsewhere in the U.K., Lowden et al. (201I) identified ten employers who had participated in identifying their top employability skills. These employers sought staff who were/had/could:

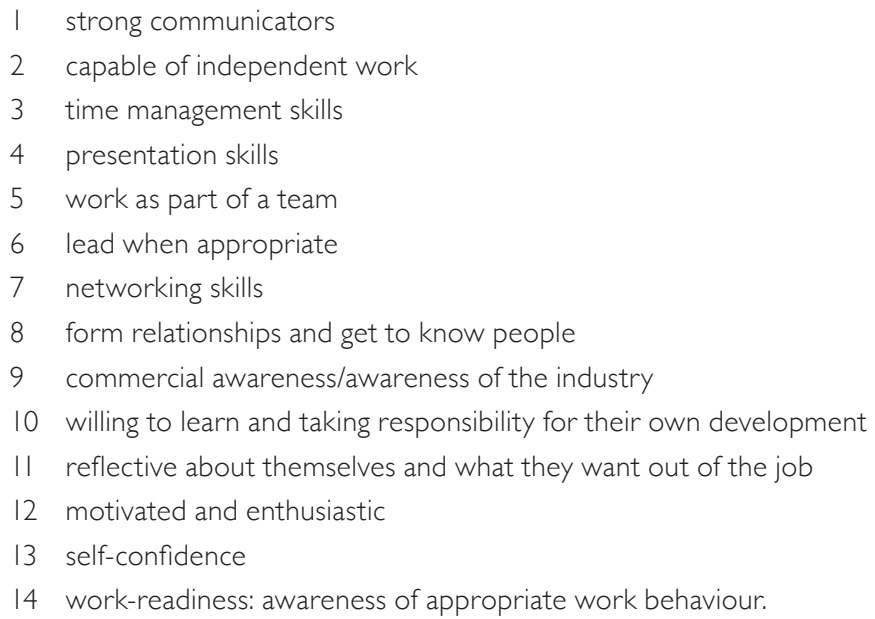

One of the key factors that Otago Polytechnic's research identified in its Learner Capability Framework: Employer Priority Index was teamwork (Otago Polytechnic, 2019). Indeed, teamwork was top priority in the Otago Polytechnic School of Business, as identified by industry, which sought graduates who could "build trust and collaborate [and] plan and complete projects by deadlines" (p. 18). According to Schultz, Wilson and Hess (2010), teams outperform individuals. They point to the advantages of team-based assignments that "incorporate skills necessary for employability like collaboration, problem solving, communication, and shared vision" (p. 17). McCann and Selsky (20I2) point out the importance of building adaptive capacity for handling chaos and change. Teams provide a wider span of skills and experience that affords greater flexibility and symbiotic co-operation.

However, Shultz et al. (2010) also acknowledge that many students feel burdened and disadvantaged by nonproductive peers, resulting in poorer academic outcomes. Velinov et al. (2019) noted that many students had an aversion to online team assignments, given that most assignments were team-based. They found that students' aversion to teamwork varied depending on their level of autonomy, based on whether working in a team was mandatory or optional.

\section{THE IMPROVING ORGANISATIONAL PERFORMANCE FRAMEWORK}

In the IOP paper, learners present a proposal for their intended research project, which includes the aim, research question(s), methodology, research methods and literature review. They undertake empirical research following successful ethical approval. Based on the data they have collected and analysed, learners produce a report and present their findings to a panel of assessors made up of host organisation employees and lecturers.

One component of the paper requires learners to undertake a 360-degree review of their performance and that of others in their team including a reflection on the team process as a whole. This review creates an opportunity for self-reflection as well as reflection on working with others, an important element in closing the loop on the experiential learning experience. According to Stefano et al. (2016), once a person has some experience of a task, 
gaining further experience with that same task is not as beneficial as discussing and reflecting on the numerous experiences associated with it. They argue that until time has been taken to truly reflect on a given task and articulate and organise it for future improvements, other immediate experiences may fail to be reflected on, as "individuals largely prefer doing to thinking" (p. 4).

The 16-week delivery of the paper involved a team of three lecturers, who delivered four two-hour classes per week. The workload was heavy for learners, so dividing them into teams of four to five, with the work equally shared, helped address these challenges. According to Cole (2019), teams can achieve more together than they can alone and, on the whole, people enjoy being part of a successful team.

Of the four classes per week, one was concentrated on data skills, two others on research design and the fourth was a tutorial. In the first two weeks, learners complete a team agreement to establish team behavioural guidelines, expectations and accountability. This process is overseen by the lecturer involved, and all teams are alloted a supervisor to meet with on a weekly basis. The first eight weeks are lecturer-directed and involve team formation and problem-solving skill acquisition, while learners work with a business. Learners spend the next two weeks collecting and analysing data associated with their project and writing a report. At this stage of the course design the lecturers take on the role of supervisors, meeting with the teams on a weekly basis.

According to Oinam (2017), using the student-centred approach to teaching and learning focuses on innovative methods of teaching, with an emphasis on effective communication and students actively participating through problem-solving, using critical and reflective thinking and being involved in their own learning. According to Educational International (20l0), student-centred learning comprises the following elements:

- The reliance on active rather than passive learning

- An emphasis on deep learning and understanding

- Increased responsibility and accountability on the part of the learner

- An increased sense of autonomy in the learner

- An interdependence between teacher and learner

- Mutual respect within the learner-teacher relationship; and

- A reflexive approach to the teaching and learning process on the part of both the teacher and the learner. (as cited in Oinam, 2017, p. 29)

Reflection processes are built into the structure and layout of the paper and are intended to inform and guide the learners to analyse, digest, learn from and articulate their experiences by linking them with the theory relating to emotional intelligence, experiential learning and personal growth in team environments. This approach is supported by Schedlitzki (2019), who asserts that the lifelong process of critical reflection is an opportunity to evolve the leadership practices and decision-making processes that managers and co-workers engage in regularly and that are beneficial for learners in their daily practice.

\section{FINDINGS}

Although teamwork is something employers want developed in their employees, learners may not yet see its value, and indeed might even resent having to participate in group assessments as part of their course work. According to Cole (20I6), avoiding conflict ignores one's own and others' concerns. Often the team agreement is completed at the start of the course, but is not referred to again, meaning that meetings may not maintain structure, based on a lack of expectations. As a result, there can be a lack of accountability and responsibility both for individuals and team tasks. This new semester paper had been taught three times to date, and it was evident that the biggest challenge learners faced was working successfully in their teams. 
The IOP paper also focusses on teaching emotional intelligence skills, using the Goleman and Boyatzis (2017) model (See Figure I). Goleman and Boyatzis (2017) focus on individuals with an array of emotional intelligence capabilities that are well balanced and targetted to help leaders face tough challenges. These capabilities need to be learned to enable the development of professional performance as a leader, at work or in an applied project situation. In addition, Pipera et al. (2019) demonstrate the relevance of emotional intelligence development during university studies to enhance the learner's prospects of a successful professional business career. While developing emotional intelligence is not a specific learning outcome of the paper, it aims to further learners' skill development and capabilities insofar as it applies to knowledge creation and awareness.

\section{Emotional Intelligence Domains and Competencies}

\begin{tabular}{|c|c|c|c|}
\hline $\begin{array}{l}\text { SELF- } \\
\text { AWARENESS }\end{array}$ & $\begin{array}{l}\text { SELF- } \\
\text { MANAGEMENT }\end{array}$ & $\begin{array}{l}\text { SOCIAL } \\
\text { AWARENESS }\end{array}$ & $\begin{array}{l}\text { RELATIONSHIP } \\
\text { MANAGEMENT }\end{array}$ \\
\hline \multirow{5}{*}{$\begin{array}{l}\text { Emotional } \\
\text { self-awareness }\end{array}$} & $\begin{array}{l}\text { Emotional } \\
\text { self-control }\end{array}$ & \multirow{2}{*}{ Empathy } & Influence \\
\hline & \multirow[t]{2}{*}{ Adaptability } & & Coach and mentor \\
\hline & & \multirow{3}{*}{$\begin{array}{l}\text { Organizational } \\
\text { awareness }\end{array}$} & $\begin{array}{l}\text { Conflict } \\
\text { management }\end{array}$ \\
\hline & $\begin{array}{l}\text { Achievement } \\
\text { orientation }\end{array}$ & & Teamwork \\
\hline & Positive outlook & & $\begin{array}{l}\text { Inspirational } \\
\text { leadership }\end{array}$ \\
\hline
\end{tabular}

Figure I. Emotional Intelligence domains and competencies (Goleman \& Boyatzis, 2017).

One of the learning outcomes of the IOP paper specifies that learners will participate effectively in a variety of team roles, and the role of lecturers and supervisors is to help the teams to learn how to manage themselves. According to Dyer et al. (Dyer et al., 2013), four factors are required to manage teams to achieve superior performance, as shown in Figure 2. 


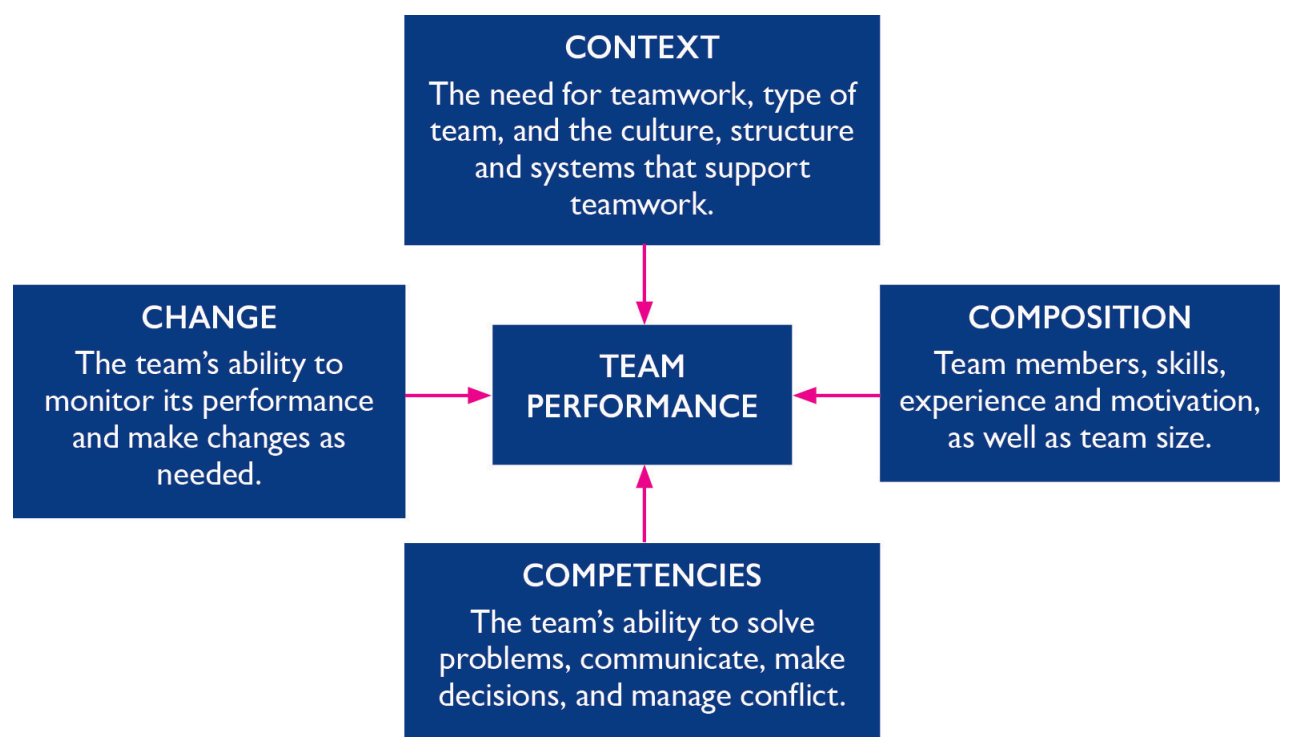

Figure 2: The four C's of team performance (Dyer et al., 2013).

By managing the characteristics of each ' $C$ ' of the model (Figure 2), the team can develop high-performance behaviours. All these behaviours are desirable aspects and outcomes for the learners.

\section{DISCUSSION}

We have seen that discontent and resentment within teams is a common factor. According to educational psychologist Bruce Tuckman (1965), teams must move through specific stages of team formation in order for them to develop high-performance behaviours. These "forming, storming, norming, and performing" stages are all necessary in order to create team synergy, a concept wherein "the whole is greater than the sum of its parts" (Federer, 2013, para. 2). The leader has an important role in utilising the powerful combined effort of the team to achieve its goals. According to Black et al. (2019), tasks and interpersonal relationships are more effectively managed by high-performing teams, demonstrating team performance and effectiveness. However, in our study, a number of factors during the teaching process stalled the teams, and many of them were not able to move beyond the "storming" stage, or fluctuated between "norming" and "storming".

Refering to Figure 2, Dyer et al. (2013) assert that teams need competencies in order to clearly articulate the team's goals and metrics, communicate effectively, give appropriate feedback, build trust and commitment, and resolve disputes and disagreements in the team.

\section{Aversion to working in Improving Organisational Performance teams}

During the delivery of the paper we observed that some learners disengaged with other members of their team, thereby avoiding communicating effectively; they did not give feedback and were unable to meet deadlines or produce high-quality work. 


\section{Change without consultation}

One particular problem was observed when team members were contributing individually to the report. Different levels of academic ability were displayed, with some students having a poor understanding of academic writing, APA referencing, giving and receiving feedback and handing in their draft work on time. Evidence from reflection undertaken in the groups led the lecturers to observe patterns of behaviour within the teams. Poor individual performance only becomes evident once the first draft of academic writing is presented. Learners who have spent their first year in the Business School are more aware of the academic expectations required by Otago Polytechnic. The diverse academic abilities within the teams create immediate concern from high-achieving students who strive to do well. Based on feedback received from their reflections, their first instinct is to correct and rework the draft submissions from the other learners' contributions. These changes, often corrected without consultation, cause polarisation and resentment within the group. According to Barnett and O'Rourke (20II), team members who do not feel included often withdraw, create subgroups or become inactive. This act of undermining within the team is two-fold in nature - it indicates a lack of social awareness and empathy on the part of the team member who is changing colleagues' work; and a lack of organisational awareness, teamwork and expectations on the part of the learner who has had their work rewritten.

\section{Missing in action}

The lecturers also observed the effect of team members' absences on the dynamics of each of the teams. The teams are instructed to have a weekly face-to-face meeting, take minutes and record their action points in a shared document. Team members inform each other via Microsoft Teams when they are absent. Those diligent learners who consistently attend classes often take on a tutoring role and bring other learners up to speed on missed content. This often leads to confusion through misinterpretation of the work missed, delays in completion of work and general discontent from those learners who attend conscientiously. Depending on the diligent learner's self-awareness of their "relationship management" (Figure I), they will take on a mentoring and coaching role to some extent. Often the diligent learner resents this additional workload until it is pointed out to them, on an informal basis, that their own personal growth and development is benefitting. Goleman and Boyatzis (2017) note that learners may be sensitive to others' needs and be problem-solvers, but may not yet have developed the emotional intelligence to give critical feedback to colleagues, "the courage to ruffle feathers and drive change, the creativity to think outside the box" (p. 3). This is not their role within the team either.

\section{The new design for the paper}

The paper redesign is focused on the teams "learning by doing and reflecting" on the learning process. The lecturer's role is to observe the group dynamics, the interactions, and actively listen to the learners' questions, offering advice and assisting them to problem-solve their challenges. Lecturers need to recognise the personal growth opportunities that occur for learners who step up into leadership roles and articulate this, so that learners become aware of the links between their own practice and the theory that is being taught.

The revised paper structure and new learning opportunities for the learners are based on the lecturers' reflections on the learners' resistance to working in diverse teams, as well as on the work of McHann and Frost (20I0), the PDSA Model for Improvement adapted from Deming's PDSA Cycle (Langley et al., 1994), Otago Polytechnic's Integrating Experiential Learning into Business courses, and the Four C's of team performance (Figure 2). The Teaching as Inquiry model (Ministry of Education., 2007) (Figure 3) helped the lecturers to reflect while they were facilitating and to come up with better ways of helping the learners process their learning, and for lecturers to enquire about the impact of their teaching on their learners. The concept of ako ("to teach and to learn") and the contributions the learners bring to the class environment were also reflected on by the lecturers, as the value of ako lies in the reciprocal and integrated relationship between learner and whānau (Hikitia, 2008, as cited in Ministry of Education., 2020). 


\section{Teaching as Inquiry}

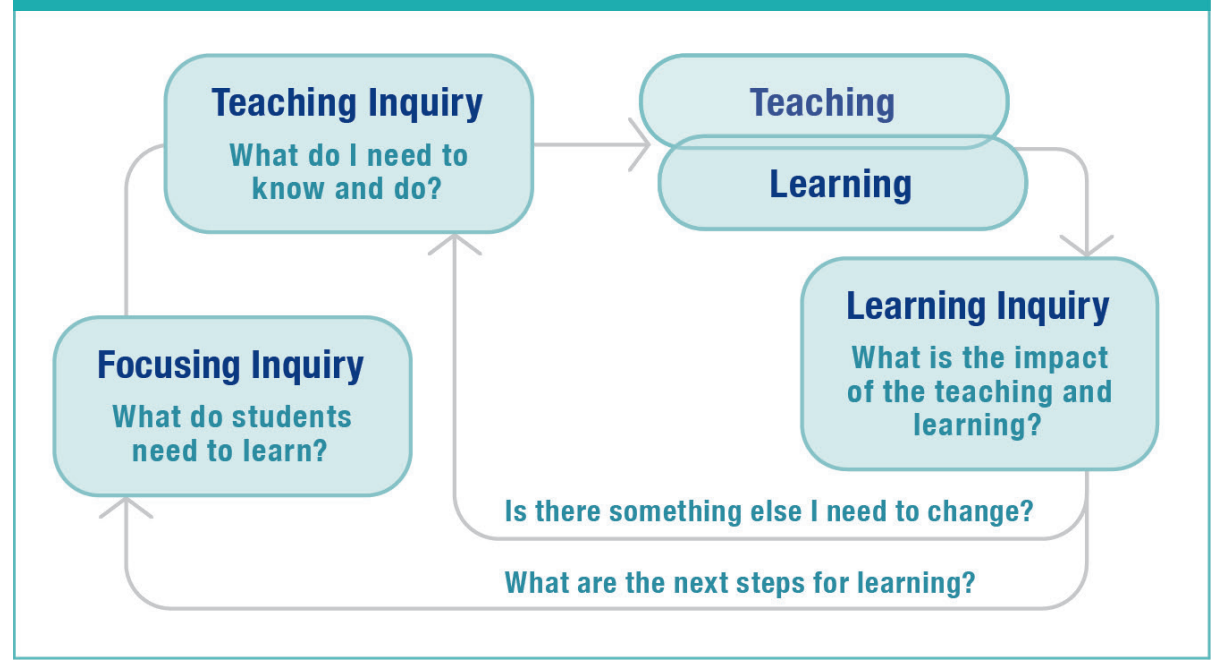

Figure 3. The Teaching as Inquiry model. Source: New Zealand Curriculum, Ministry of Education, 2007, p. 35.

Deming's Plan, Do, Study, Act model and structure (The W. Edwards Deming Institute, 202I) was used as part of the redesign of the IOP paper and will be adopted as part of learning processes. According to Chicquette (20I0), learners can apply the model's planning stage to assessment and data analysis, adding a plan of action based on their limited evidence, using milestones to assess if their goals and objectives are tracking well and adjust if necessary. The model could also be applied as part of their project management plan to keep track of and assess their own quality improvements.

The Plan cycle stage (see Figure 4) could be used to develop a quality development plan or project management plan. In this stage, the teams are "forming" - setting out their expectations, designing a team agreement and assessing individual strengths and weaknesses. Meeting times are set up, with role allocation and delegation of tasks. The cycle continues in the Do stage and the plan is implemented; this stage could be the "storming" stage of Tuckman's (1965) theory. The Study stage allows for a review of the plan against the assessment criteria and criteria set by the supervisors in the weekly meetings; at this stage the teams should be "norming" and starting to become productive. The final stage is Act, where the plan is modified to meet the assessment criteria, with feedback from the supervisors; there may be some movement back to the "storming" stage here, or a shift to a state where the team is "performing" well together (Chicquette, 20I0). Much of this progress is dependent on individual motivations, levels of self-awareness and previous academic experiences. 
If the School of Business can implement the strategic move of preparing students for academic success prior to IOP commencing each semester, then this could assist with their self-confidence and adjustment to a new learning environment.
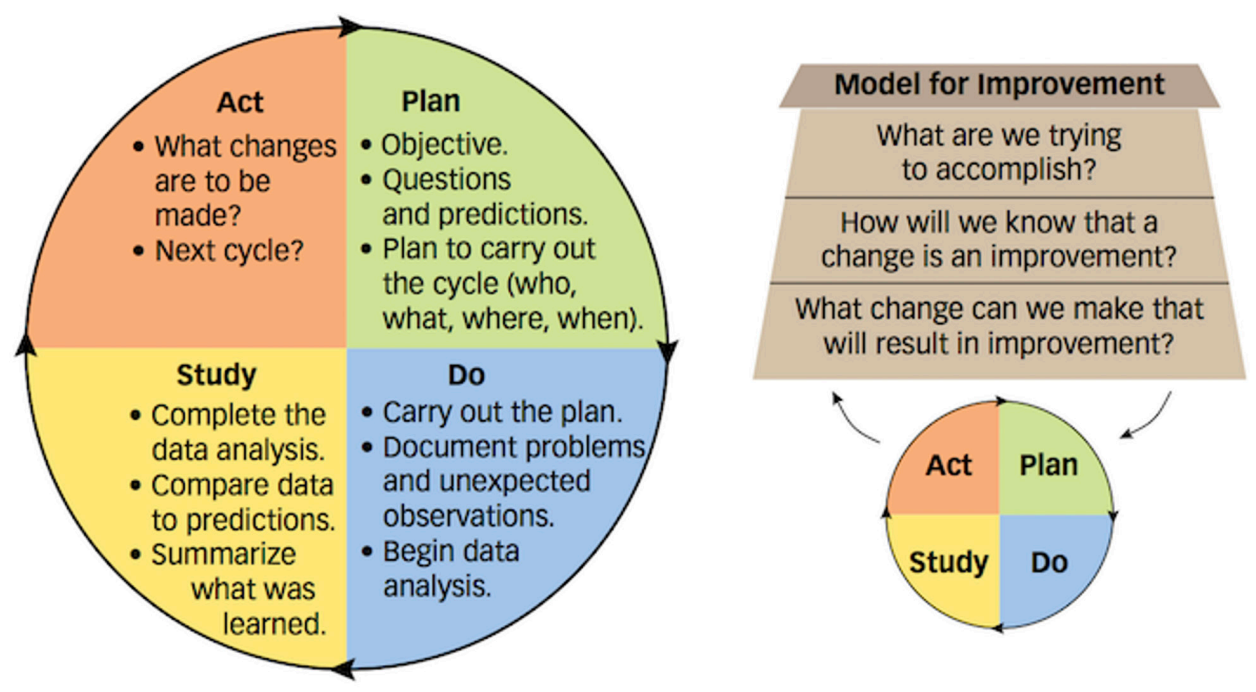

Figure 4. The PDSA Cycle and Model for Improvement (Langley et al., 1994).

\section{FUTURE WORK}

The IOP paper will continue with the theoretical teaching component - introducing the course outline, reflective journals and theories - thus enabling learners to acquire the important information they need about the course subject matter (context).

Weekly meetings with both lecturers to engage in question-and-answer sessions, with problem solving and re-phrasing the learners' questions back to them, will continue, as they assist learners with their interpretation of the important information derived from the course. Changes in the structure of the weekly meetings will be made to encourage the learners to engage in making journal entries about an idea, concept or principle that they have learnt during the week, presenting a two-fold learning opportunity. Firstly, learners are able to reflect on and apply or begin to apply some of the learning from their studies during that week to their personal or professional life; and, secondly, drawing on their immediate experiences, they are providing evidence for themselves that they will be able to look back on and recall for their reflective assessment at the end of the paper. The learners will be asked three questions to help them focus, be directed in their answers and reflect on their performance as a team so far: What did you achieve last week? What do you plan to do this week? What are your challenges? The meetings will be learner-led, with a rotation of team members chairing the meeting each week, ensuring that all students are being held accountable and taking some leadership role within their team. Additional time will also be spent on the effective use of journalling as a reflective tool. According to McHann and Frost (2010), "this [reflective] tool can be put to powerful use to teach application and inculcate habits of learning by doing" (p. 6).

Additional emphasis will be focused on the team agreement and its purpose as a working document that must be brought to each team meeting; this will have the benefit of assisting learners to project-manage weekly face-to-face meetings using an agenda and minutes. According to Barnett and O'Rourke (20II), because it is more 
difficult to gain "shared meaning" within a diverse team, it is important for the lecturers to spend time in helping the teams to pinpoint their strengths and weaknesses and draw up their team agreement with their explicit expectations of how each member will take responsibility and accountability in their roles. It was recognised that during high-pressure moments, such as learners analysing their data and the challenging task of working together collaboratively, lecturer support becomes more crucial for learners. This is often the time when some of the learners disappear or are unable to prioritise their different workloads, and so conflict can occur. According to Barnett and O'Rourke (20II), it is important for learners to balance too much conflict against too little conflict in order for them to achieve synergy, and so that the collective and collaborative approach to working productively can assist in achieving team outcomes.

New ideas about how to counter the problem of different levels of academic understanding within each team will be trialled by introducing in-class exercises where all learners are given pieces of academic work to give feedback on, with the opportunity to discuss them in-class under the direction of the lecturer. Learners will next create a piece of academic work based on their first assessment - a draft of the research methods that they will use and then distribute it among the team for feedback. While this activity could help to identify areas of academic weakness, it also offers a learning opportunity about how best to give constructive feedback on work among team members.

The importance of doing and the nature of real application are key to gaining employability skills and achieiving team cohesion (Moen \& Norman, 2010). McHann and Frost (2010) assert that learning how to apply learning must be self-directed and "caught" rather than "taught." The challenge lies in observing this self-taught learning, identifying it and discussing it to determine whether it encompasses a positive or negative observation of the individual or group dynamic. While the team should try to be self-managing, the course lecturers are able to intervene when required.

The interventions associated with the redesign of the IOP paper will continue to be monitored through lecturers' reflective practice, learner feedback and considerations relevant to the future employability of the learners.

Helen Geytenbeek is a senior lecturer in the School of Business at Otago Polytechnic, specialising in business and tourism with a special interest in course design. Her extensive industry experience underpins and informs her theory and practice. Learners benefit from her expansive networks.

(1) https://orcid.org/0000-0003-0905-3347

Lesley Gill is an associate professor in the School of Business, Otago Polytechnic. Her PhD explored emotional intelligence training design. She has co-edited and contributed to a textbook, Organisations and Management, and Collective Voices of COVID-19. Her latest book, Exploring Practical Perspectives of Emotional Intelligence: Harnessing the Power Within, was released in May 2021. Lesley leads the Master of Applied Management postgraduate degree and supervises masters and doctoral students in Capable NZ.

(1) https://orcid.org/0000-0002-0257-6965

Rachel Byars is a principal lecturer on the Bachelor of Applied Management programme at the School of Business, Otago Polytechnic. Rachel's primary focus is on business and event education and learner motivation.

(D) https://orcid.org/0000-0002-6004-9063

Melissa Clarke-Fuller is a lecturer in the School of Business, Otago Polytechnic, focusing on marketing and business research across all year-levels. Her areas of interest include leadership and employability skill development.

(1) https://orcid.org/0000-0002-0576-2544 


\section{REFERENCES}

Barnett, S., \& O'Rourke, S. (201I). Communication Organisation and Innovation (3rd ed.). Pearson.

Black, S., Gardner, D. G., Pierce, J. L., \& Steers, R. (2019). Organisational behavior. Team development over time. OpenStax.

Chicquette, L. J. (2010). The design and implementation of an effective continuous school improvement process [Ed.D., Cardinal Stritch University]. In ProQuest Dissertations and Theses. https://www.proquest.com/dissertations-theses/designimplementation-effective-continuous-school/docview/828353307/se-2?accountid=39660

Cole, K. (2019). Management: Theory \& practice (7th ed.). Cengage Learning.

Dyer Jr, W. G., Dyer, J. H., \& Dyer, W. G. (2013). Team building: Proven strategies for improving team performance. John Wiley \& Sons.

Federer, D. (2013, December 6). How to build team synergy. Business Observer. https://www.businessobserverfl.com/section/ detail/how-to-build-team-synergy/.

Goleman, D., \& Boyatzis, R. (2017). Emotional intelligence has 12 elements. Which Do You Need to Work On? Harvard Business Review. https://hbr.org/2017/02/emotional-intelligence-has-12-elements-which-do-you-need-to-work-on

Langley, G., Nolan, K., Nolan, T., Norman, C., \& Provost, L. (1994). The Foundation of Improvement. Quality Progress, 8I-86.

Lowden, K., Hall, S., Elliott, D., \& Lewin, J. (20II). Employers' perceptions of the employability skills of new graduates. University of Glasgow and Edge Foundation.

McHann, J. C., \& Frost, L. A. (2010). Integrating experiential learning into business courses: Using learning journals to create living case studies. American Journal of Business Education (AJBE), 3(8), I-12.

McCann, J., \& Selsky, J. W. (2012). Mastering turbulence: The essential capabilities of agile and resilient individuals, teams and organizations. Jossey-Bass.

Ministry of Education. (2007). The New Zealand curriculum for English-medium teaching and learning in Years I-13. Learning Media.

Ministry of Education. (2020). Te Aho Arataki Marau mō te Ako i Te Reo Māori - Kura Auraki. https://tereomaori.tki.org.nz/ Curriculum-guidelines/Teaching-and-learning-te-reo-Maori/Aspects-of-planning/The-concept-of-ako

Moen, R. D., \& Norman, C. L. (2010, November). Circling back: Clearing up myths about the Deming cycle and seeing how it keeps evolving. QP [Quality Progress], 22-28.

Oinam, S. (2017). Student-centered approach to teaching and learning in higher education for quality enhancement. IOSR Journal of Humanities and Social Science, 22(6), 27-30.

Otago Polytechnic. (2019). Learner capability framework: Employer priority index (pp. I-32). https://www.op.ac.nz/assets/ e46319f5II/Learner-Capability-Framework-Employer-Priorities-Index.pdf

Schedlitzki, D. (2019). Developing apprentice leaders through critical reflection. Higher Education, Skills and Work-based Learning, 9(2), 237-247.

Schultz, J., Wilson, J., \& Hess, K. (2010). Team-based classroom pedagogy reframed: The student perspective. American Journal of Business Education, 3(7), 17-24.

Stefano, G. D., Gino, F., Pisano, G. P., \& Staats, B. R. (2016). Making experience count: The role of reflection in individual learning. (NOM Unit Working Paper No. 14-093). Harvard Business Review. https://doi.org/I0.2139/ssrn.24I4478

The W. Edwards Deming Institute. (202I). Deming on Management: PDSA cycle. PDSA Cycle. https://deming.org/deming-onmanagement-pdsa-cycle/

Tuckman, B. W. (1965). Developmental Sequence in Small Groups. Psychological Bulletin, 63(6), 384-399.

Velinov, E., Elenurm, T., \& Denisov, I. (2019). Dealing with students' aversion in global virtual teams: Evidence from Czech Republic and Estonia. Advances in Social Science, Education and Humanities Research, 298(I), 363-366. 